\title{
CORRESPONDENCE.
}

\section{LONG MULTIPLICATION OF MONEY}

To the Editor of the Mathematical Gazette.

Dear Sir,-OOn p. 256 of your October number Mr. Webb gives a long multiplication of money sum done by what he follows Dr. Ballard in calling the "Wholesale Method" I should like to draw your readers' attention to an arrangement which differs only slightly from that given by Mr. Webb, but which seems to me to have distinct advantages.

Taking the sum he gives, I start thus

\begin{tabular}{rrrr}
$£$ & s. & d. & f. \\
78 & 16 & 9 & 3 \\
& & & 249 \\
\hline 17430 & 2490 & 2241 & 747 \\
1992 & 1494 & &
\end{tabular}

I lay great stress on :

(i) The 249 is multiplied by the numbers of $f$, s., d., and farthings.

(ii) This multiplication is done all at once before any transference from column to column is made.

Then the 747 farthings are changed to $186 \mathrm{~d}$. and 3 farthings, and these pence are transferred to the pence column as indicated by the arrow (see below), and so on. The whole sum appears thus :

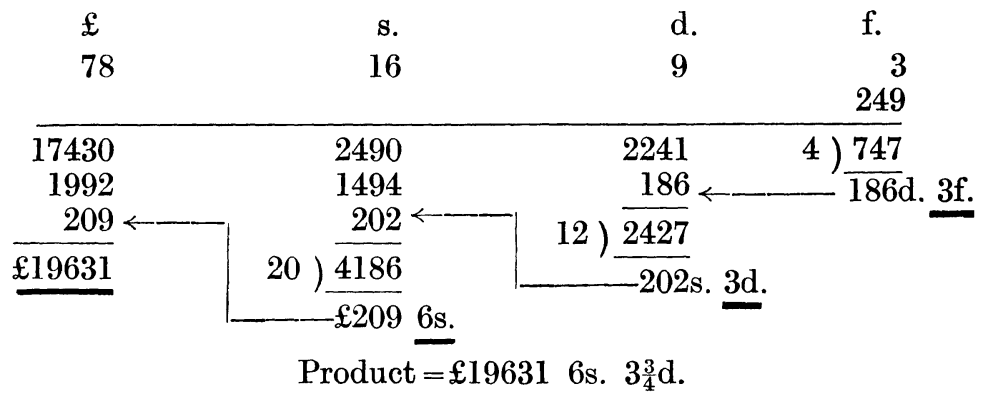

When the method becomes familiar the arrows may be omitted.

The fact that all the multiplication is done at one time seems to me a distinct advantage.

I have placed the multiplier (249) below the sum of money as I have always done, but I think Mr. Webb's idea of placing the multiplier above the sum of money is probably better.

Perhaps Mr. Webb will have opportunity of trying out my arrangement against the one he gives.

It is not without interest that Dr. Ballard and $I$, working quite independently of one another, both arrived at arrangements which 
are nearly identical. I have used the above arrangement regularly since 1924, Dr. Ballard gave his in his Teaching the Essentials of Arithmetic published in 1928 , my arrangement first appeared in print in Godfrey and Siddons' Teaching of Elementary Mathematics in 1931. Sir Percy Nunn's arrangement for long division of money certainly suggested the idea to me and probably also to Dr. Ballard.

I doubt whether "Wholesale Method", as used by Dr. Ballard and Mr. Webb, is a good description of the method; it has been described as the method in which the numbers of $£$ s. d. are used as multipliers-an excellent description, though too long for a name.

$$
\text { Yours truly, A. W Siddons. }
$$

\section{To the Editor of the Mathematical Gazette.}

Dear Sir,-I have seen a copy of Mr. Siddons' letter to you concerning his method for long multiplication of money

I was at once attracted to this method and felt it worth while carrying out what tests I could in accordance with Mr. Siddons' suggestion.

Unfortunately I was unable to make the tests as extensive as I - desired, but the report of what I have managed to do may be of interest to your readers.

Yours truly,

H. WeBв:

[Mr. Webb's report, in which he analyses the results of these further tests, will appear in the May issue of the Gazette.-ED.]

1340. For instance, many people believe that some families are more liable than others to run exclusively to boys or to girls. Yet an analysis of 53,680 families, each having eight children, showed that 557 were all boys or all girls. By mathematically pure chance the numbers would have been 419 , which is in good agreement.- Review of You and Heredity, by A. Scheinfield, in The Manchester Guardian Weekly, 15th September, 1939. [Per. Mr. R. A. Fairthorne.]

1341. Condorcet the mathematician solved a mathematical problem which had worried him the day previous, during a somnambulistic trance, and had no recollection of the fact the following morning.-E. C. Spitzka, Insanity, Pt. I, Ch. 6, p. 58 ; quotation from the Century Dictionary. [Per Mr. E. B. Escott.]

1342. How MANY Is " MOST"?

Reno, the city of divorce and love tangles, claims that it is entitled, by merit, to be called "The Gretna Green of the West" Despite its publicity about divorces, marriages there exceed divorces by six to one. Most of the marrying people there, adds the B.U.P., are those who have just been divorced. -Evening News, 6th January, 1940. [Per Professor L. M. Milne-Thomson.]

1343. Did one say quantities of gooseberries or numbers? The only thing his mother, so far as he could remember, had ever taught him, during the period he was at her knee, was not to say quantities if what he meant was numbers.-The Jasmine Farm, p. 9, by the author of Elizabeth and her German Garden. [Per Mr. A. R. Miller.] 